\title{
Editorial
}

\section{A transilience? Or a natural progression?!}

W ith this issue, our contract with MedknowWolters Kluwer publications, who were publishing the IJPS for fifteen years since 2004, has come to an end. On behalf of the APSI and all previous editors, I would like to express my heartfelt gratitude to the team of Medknow-WK for their kind cooperation and assistance.

Next issue onwards the IJPS will be published by new publishing partner-Thieme Medical Publishers Inc. Now on, all articles will be published ahead of print as 'e-first', which are citable and visible on PubMed prior to the print issue. This will reduce publication time and provide authors a greater potential for citations.

The journal has progressed by leaps and bounds during the last 50 years, thanks to the outstanding work done by the previous editors. I am sure this transilience will bring more visibility, global appeal, greater acclaim and international contribution. Further, the publication will remain an open access, accept submissions without publication fees, and I can vouch for unbiased editorial decisions.

While we are diligently working on smooth transition, I seek authors' cooperation for their currently submitted manuscripts under process. We assure you of timely resolution and editorial decisions insofar as possible.

We invite new manuscripts to be submitted for: www. manuscriptmanager.net/ijps/. Kindly follow authors' instructions for a seamless submission process. The publication will be hosted on a new web link on www. thieme.com/journals. This will be updated soon.

On this occasion, I would like to invite new reviewers to IJPS family. I appeal to the immensely talented pool of young researcher to spare time for the journal, which will certainly boost the quality and performance. In due course, section editors will be introduced to manage greater proficiency of specific areas and to facilitate wider spectrum of articles.

Once again, my earnest request for authors to submit original research articles, systematic reviews, metanalysis, and experimental research of Level- 1 evidence. Case series and reports remain to be low priority for publication, except for the exceptional ones. Nevertheless, we encourage new ideas, innovations and technical notes for value addition to the readers.

I look forward for your suggestions, inputs and contribution to continue to raise the quality bar and to make the journal an epitome of scientific knowledge on the global platform.

Dinesh Kadam

Editor IJPS, Professor and Head, Department of Plastic and Reconstructive Surgery, A J Institute of Medical Sciences and A J Hospital and Research Centre, Mangalore,

Karnataka, India.

E-mail: drkadam@yahoo.co.in

This is an open access journal, and articles are distributed under the terms of the Creative Commons Attribution-NonCommercial-ShareAlike 4.0 License, which allows others to remix, tweak, and build upon the work non-commercially, as long as appropriate credit is given and the new creations are licensed under the identical terms.

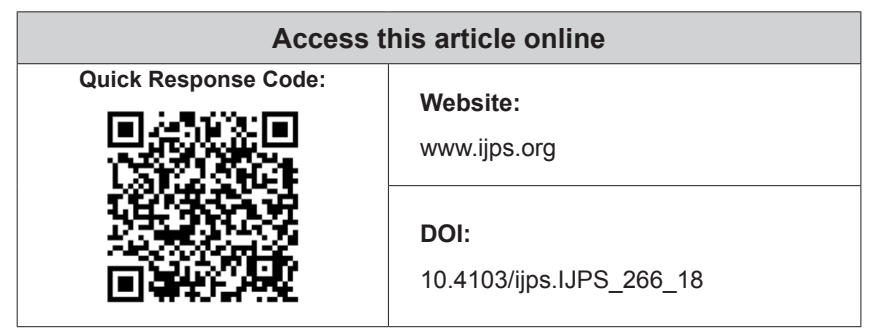

How to cite this article: Kadam D. A transilience? Or a natural progression?! Indian J Plast Surg 2018;51:263. 